\title{
Metering and the principal-agent problem in restructured energy markets ${ }^{1}$
}

\begin{abstract}
Metrology services, commonly known as the provision of electricity and gas metering, has traditionally been the domain of monopoly distribution network operators. Logic dictates that it is more efficient for a single entity to physically attend each home and business to read electricity and gas meters. However, when we tested this thesis in Australia's National Energy Market (NEM) by examining service quality and costs arising from the interaction between agent (monopoly distribution networks) and principal (energy retailers), we found a classic principal-agent problem. Service quality is poor, with one-in-13 meter reads being estimated or erroneous. We find NEM wide agency costs of \$16 million per annum and deadweight losses of $\$ 118$ million per annum being accumulated by principals, let alone what must be a much higher cost of consumer inconvenience. We establish that the regulatory framework, rather than asymmetric information, is the root cause of the problem and that a sound case exists for policymakers to review the entire metering framework to correct adverse implications for energy customers. This case is strengthened by the emergence of new metering and embedded generation technologies which are fundamentally changing the nature of consumer interaction with the energy industry.
\end{abstract}

Keywords: Utility Metering, Agency Theory

JEL Codes:

\section{Introduction}

The principal-agent problem has long been established as a means by which to analyse situations where contracts exist between parties with different objectives or quantity and quality of information, dating back as least as far as Berle and Means (1932). Principal-agent relationships can create losses of allocative and productive economic efficiency as a result of the agent performing functions in a way that are not in the best interests of the principal. Agency theory notes that this situation can arise for a number of reasons including information asymmetry, split incentives and regulatory requirements amongst others (Murtishaw and Sathaye, 2006).

In this article, we argue that the definition of roles within electricity and gas metering has been an overlooked element of the reform process in the Australian energy industry. To date, reforms have focused on industrial organisation and the establishment of a real-time wholesale energy market with an objective of increasing productive, allocative and dynamic efficiency - especially as it relates to wholesale prices and the allocation of scarce capital. Monopoly distribution network businesses were made responsible for traditional metering services at the household level through a prescribed regulatory framework underpinning the operation of the National Energy Market (NEM). The historic and dominant economic logic relates to the efficiency benefits of having a single entity physically attending properties in a street to read the mechanical meters. This logic is prima facie sound. But we believe that little attention has been paid to the costs that arise through the principal-agent problem that such a regulatory entitlement creates. Furthermore, the advent of digital metering and lower-cost embedded generation creates even greater impetus for policy change to ensure the regulatory framework keeps pace with technological change.

\footnotetext{
${ }^{1}$ Earlier forms of this analysis were presented to the Australian Energy Market Commission during the Power of Choice review undertaken in 2012/13. The authors are grateful to AEMC staff who reviewed earlier drafts and provided useful insights and suggestions.
} 
In this article, we analyse data from AGL Energy Ltd's billing engine and Customer Call Centre, which services 3.4 million customers in the NEM. The period provided by AGL relates to a 12 month sample period of meter reads and translates to just over 16 million meter readings and 4 million customer telephone inquiries. Our analysis is structured as follows. Section 2 reviews industry structural reforms while Section 3 frames the regulatory responsibilities of electricity and gas network operators and energy retailers within the principal-agent problem. In Section 4, we analyse the service quality of electricity and gas metering and assess the transfer of costs between principal and agent. The prevalence of estimated and wrong reads is considered within section 5 including estimates of inefficient intra-industry costs and costs to society as a result. Section 6 analyses completion rates of non-metering related orders raised by retailers and completed by distributors. Policy recommendations and concluding remarks are provided in Section 7.

\section{Structural reforms}

Australia's microeconomic policy agenda in the 1990s led to the structural reform of the electricity and gas industries. ${ }^{2}$ Once vertically integrated and owned by the state, State Electricity Commissions disaggregated their power generation, transmission grid, distribution network and retail supply functions and in many cases these newly created businesses were privatised. The gas industry was also been divided on similar lines. However, the industry structural reform 'blueprint' from the 1990s bears little resemblance to industrial organisation in 2014. Taking electricity as an example, the generation fleet and the transmission grid were structurally separated from the outset, but initially, franchise retail supply businesses were stapled to a host monopoly distribution network. This "retail-distributor model" was quite common at the time of reforms in the mid-1990s, with the British electricity market providing the template. Retail suppliers and monopoly distribution networks had a key characteristic in common - the customer meter. However, this was where the commonality generally ended. Distribution network companies, or 'pipes, poles and wires' businesses as they are often referred to, are regulated monopoly infrastructure investments characterised by relatively stable financial returns on a highly capital-intensive asset stock, involving a vast asset management and maintenance task with a focus on the efficient and reliable (physical) supply of energy to society. Energy retailers on the other hand are customer-focused marketing businesses, operating within a competitive environment with acute real-time energy commodity market exposures - the financial returns from which are relatively less stable. Over time, all monopoly distribution network companies in the NEM have divested their retail supply businesses due to the vastly different risk profiles and skills-sets required. ${ }^{3}$

For the purposes of our subsequent analysis, this structural history is quite important. When retail supply and monopoly distribution networks were stapled together at NEM commencement, no intra-industry principal-agent problem existed because any metering problems encountered by an integrated retailer-distributor would be resolved internally. And when customers first became contestable in the NEM, commencing with the very largest industrial consumers, retail suppliers could operate outside their franchise monopoly distribution network 'patch' without any real principal-agent metering issue because 'at the large end of town', remotely-read interval meters had long been the norm. Additionally, the meter reading services required to operate successfully in the early phases of retail contestability were 'contestable'. Meter Data Providers have clear contractual arrangements and a customer service focus and are engaged by the 'Financially Responsible Market Participant' under commercial arrangements. Households on the other hand had mechanical or 'dumb' meters, and physical attendance was required to read the meters. And it is important to note that Australia's microeconomic reform of the east-coast energy market preceded the development of relatively low-cost smart metering that exists today.

${ }^{2}$ Structural reforms also involved horizontal separation of generation and retail.

${ }^{3}$ The two exceptions to this are Ergon Energy (due to its remote franchise customer base) and Aurora Energy in Tasmania. We note however that one recommendation in the 2011-2012 inquiry into the state of the Tasmanian electricity market recommended divesting the retail business. 
In the reform of any energy market, customer liberalisation typically follows a carefully scheduled timetable to ensure an orderly transition from monopoly supply to contestability. Only the largest industrial customers are made contestable in the first instance. Then, typically 12 months later, medium sized commercial and industrial customers become contestable. Following this, small business would be liberalised. And then eventually, 'Full Retail Contestability' would be reached whereby all households were able to choose their retail supplier. In the NEM, this process commenced from the mid-1990s, and was completed in Victoria and New South Wales in 2002, South Australia in 2003, and Queensland in 2007 (esaa, 2008). ${ }^{4}$ The adverse consequences of the principal-agent problem as it relates to customer metering can be loosely traced back to when Full Retail Contestability occurred. Once a market had achieved Full Retail Contestability, the retail supply businesses became high-risk because the monopoly over their franchise (residential) customers had, by definition, been terminated. As a result, in most cases this was the point in time in which energy retailers were divested from the franchise monopoly distribution network business.

In assessing why a principal-agent problem might exist, it is helpful to examine the underlying revenue characteristics of competitive energy retailers and monopoly distribution networks. Energy retailers purchase their wholesale electricity and gas through the Australian Energy Market Operator (AEMO) and commodity hedges prior to receiving payment from customers. Settlement of wholesale electricity occurs on a weekly basis while monopoly network charges are paid on a monthly basis. Invoices to customers on the other hand generally occurs on a threemonth billing period because physically attending meters more frequently than this would add considerable transaction costs, and there are regulatory barriers to allow for more frequent customer billing without Explicit Informed Consent.

Given the gap between weekly and monthly cash outflows to wholesale markets and monopoly networks respectively, and the three-monthly cash inflows from residential customers, energy retailers face especially strong incentives to ensure timely and accurate information is utilised for billing. Any failures with timely and accurate customer meter data results in costs associated with bill disputes, delayed cash receipts, poor customer experience, greater customer complaint call volumes and an increase in the velocity of customer switching. Furthermore, bad debts that arise as a result of metering delays or meter errors are borne entirely by energy retailers, i.e. monopoly distribution networks (and power generators) have zero exposure to end-use customer bad debt. ${ }^{5}$

The inherent incentives facing monopoly distribution networks in relation to customer metering are therefore naturally weak to begin with, and compounding this is the fact that monopoly distribution networks receive their income based upon regulated network pricing and in some cases these price levels are calibrated annually (with a one year lag) to ensure monopoly revenue targets are achieved. There is surprisingly little in the way of genuine visible incentives for a monopoly network distributor to provide accurate and timely information at the individual household meter level, since their aggregate revenue is derived from whole-of-network use and by the time an estimated read might be revealed as erroneous, in practice it is too late to be contested in practice. Assuming errors are normally distributed, their aggregate network revenue is unaffected by late or inaccurate metering information.

Above all, there is nothing other than a best endeavours requirement to provide timely and accurate customer meter data to retail suppliers in the energy market rule book. Put simply, no penalty charge or consequence exists for meter reading failures. And ironically, the cost of

\footnotetext{
${ }^{4}$ Tasmania has not yet implemented Full Retail Contestability although a process is currently on-foot (at the time of writing) with a view to removing the last customer franchise.

${ }^{5}$ A monopoly distribution network business would face bad debts if an energy retailer was declared bankrupt.
} 
correcting metering errors is fully re-chargeable to energy retailers - the market rules allow for a monopoly distribution network business to "complete" a chargeable work request with a completion code that indicates non-completion, and in the event, are able to bill the relevant retailer for this non-completed item.

Energy retailers and monopoly distribution network businesses therefore have a non-trivial disconnect in relation to their respective operational objective functions. Yet given the current regulatory framework, both are acting completely rationally. But this separation of objectives results in cost transfers from the agent (distributor) to the principal (retailer), and in deadweight losses associated with the two-sided cost of dealing with the adverse customer experience. Data presented later in this article reveals that the customer experience within the Australian energy industry is being hampered by ambiguous accountability for service quality in the regulatory rule book as it relates to metering. This article, to the best of our knowledge, represents the first assessment of metering failure costs arising from an inadequate regulatory framework and the principal-agent relationship between energy retailers and monopoly distribution network businesses in Australia.

\section{Principal and agent: metering in Australian energy markets}

The roles and responsibilities of energy retailers and monopoly distribution network businesses are defined within various legislative and regulatory instruments in the energy market. The National Electricity Law and the National Gas Law are the primary pieces of legislation which give force to the rules and operation of the NEM. ${ }^{6}$ These laws are essentially enacted through State-based legislation in each jurisdiction. Operating underneath these laws are the National Electricity Rules and National Gas Rules. Much of the prescription in relation to roles and responsibilities are defined in these subordinate legal instruments.

The complex regulatory framework underpinning metering arrangements in relation to electricity is outlined in the National Electricity Rules. The Rules state that management of meters is the responsibility of the 'Responsible Person' - who is required to engage a 'Meter Provider' that physically provides a meter and any related communications equipment, and engage a 'Meter Data Provider' that arranges for the collection and transmission of meter data to (1) the relevant energy retailer, (2) the Australian Energy Market Operator (AEMO) and (3) the relevant monopoly network distribution company. In addition, the Meter Data Provider will also provide meter data to any party authorized by the energy retailer or the customer.

Metering technologies are not uniform. The various meter technologies are defined within the National Electricity Rules as Types 1 - 7 depending upon their technical characteristics. Broadly speaking, metering technologies can be broken down into four categories (Huysmans, 2005):

- $\quad$ Type 1-4 meters record energy use each half-hour and send those readings to a central database on a daily basis. They are remotely read interval meters, or remote read interval meters with additional functionality also known as Smart Meters;

- $\quad$ Type 5 meters record energy on a half-hourly basis, but are read in-situ by Meter Readers on a routine basis (e.g. quarterly). These are locally read interval meters;

\footnotetext{
${ }^{6}$ The scope of the analysis in this paper is the jurisdictions that make up the NEM. These jurisdictions are Queensland, New South Wales, Victoria, South Australia, Tasmania and the Australian Capital Territory. Other jurisdictions (Northern Territory and Western Australia) are not physically connected to the NEM.
} 
- $\quad$ Type 6 meters simply record energy consumed from one read to the next, and are read insitu by Meter Readers. These are known as accumulation or 'dumb' meters, ${ }^{7}$ and

- $\quad$ Type 7 metering essentially refers to unmetered sites, where no meter is installed. This is not common and specific to particular types of energy consumption such as public lighting.

Under the National Electricity Rules, the market participant that is financially responsible for the customer, the energy retailer, is also responsible for deciding who to appoint as the 'Responsible Person' for remotely read Type 1-4 meters. Such services are generally contracted to specialist 'Meter Data Provider' companies who tender for this contestable service. ${ }^{8}$

But manually read meters, which cover most of the residential market, are different. Section 7.2.3 of the National Electricity Rules explicitly grants a monopoly for distribution network businesses in relation to Type 5 (manually read interval meter) and Type 6 (basic/accumulation) metering by defining the host distribution network business as the Responsible Person. The majority (c.80\%) of households and businesses in Australia have a Type 6 meter installed. We noted earlier that prima facie, there are sound efficiency reasons for such an arrangement in relation to Type 6 meters since physical attendance to read meters is required. Certainly, it is difficult to imagine multiple competing energy retailers sending their own meter readers down a single street at lower cost. But conversely, this ignores the potential to create contestable 'meter reading milk-runs' and more importantly, assumes that monopoly distribution network businesses have the same incentives in terms of meter reading timeliness and accuracy (and in turn, customer experience) as other potential models of service delivery. It also ignores the declining cost structure of smart meter alternatives and the importance of encouraging consumer choice and innovation in the provision of metering services.

The regulatory framework underpinning the operation of gas metering is less complex than electricity, but similar arrangements are in place. Section 292 of the National Gas Rules explicitly states that monopoly gas network distributors are responsible for the provision of metering services to energy retailers.

These regulatory frameworks enshrine a principal-agent relationship in both the electricity and gas markets. For most residential meters in Australia, the principal (energy retailer) is required to engage the agent (monopoly distribution network) to obtain information about electricity and gas usage recorded through meters owned and operated by the network monopoly business. However, while the regulatory settings establish this principal-agent relationship, the contractual terms by which these services are completed are not codified within the National Electricity Rules or National Gas Rules. Instead, these standards are negotiated either through retailer-distributor discussions, or are established by the Australian Energy Market Operator. It should be obvious that a negotiation between a competitive energy retailer and a monopoly distribution network is just that, a negotiation with a monopolist, and that the Australian Energy Market Operator is correctly focused on issues unrelated to customer service (such as reliability). Why service levels associated with the crucial metering component of energy supply to the 8 million households in the NEM is set within such a governance framework remains a mystery in the context of Australia's otherwise highly successful energy market reform.

At the time of writing, a new framework was being devised in Australia in relation to the noneconomic regulation of energy participants. The National Energy Customer Framework was

\footnotetext{
${ }^{7}$ For the purposes of market settlement, the energy consumption measured by accumulation meters is converted into an interval profile based on sample interval meters. In some cases, a separate meter is installed to enable off-peak products to be offered for hot water systems and pool pumps.

${ }^{8} \mathrm{See}$ http://www.aemo.com.au/en/Electricity/Retail-and-Metering/Metering-Documentation-andguides/ /media/Files/Other/electricityops/0600-0004\%20pdf.ashx
} 
passed by the South Australian Parliament in March 2011 with other jurisdictions scheduled to implement the Framework for introduction by mid-2012 (AAR, 2011), although it was delayed in several jurisdictions. Interestingly, under the new Framework, energy retailers are required to provide a bill at least every 3 months or at a frequency otherwise agreed with the customer for market contracts (NECF, 2011). But while service quality standards are clearly defined for energy retailers, there remains no extension of requirements to monopoly distribution network businesses in relation to the provision of metering data which is clearly a necessary precondition for timely billing to occur. Specifically, Rule 97 of the National Energy Customer Framework states that:

\section{"...the distributor and the retailer must each use their best endeavours to provide or make available to the other at no cost and in a timely manner information or documentation that the other reasonably requires to carry out its obligations under the Law, the Regulations, these Rules and the Retail Market Procedures."}

In other words, the National Energy Customer Framework requires the agent to make nothing more than 'best endeavours'. From an agency theory perspective, the absence of performance standards or penalty provisions for non-compliance makes Rule 97 almost redundant in our view. State-based regulatory authorities nonetheless continue to audit energy retailers, and have sought to take action against energy retailers for failing to comply with provisions around the timing of bills issued, despite the fact that no recourse exists to monopoly distribution network businesses. ${ }^{9}$ The NSW independent regulator, IPART's $(2011, \mathrm{p} .3)$ has highlighted the inherent mismatch of legal obligations between energy retailers and monopoly distribution network businesses.

The ideal long-term solution to overcome this basic principal-agent relationship is to replace all Type 6 mechanical meters with Type 4 smart meters. With smart meters installed, remotely read metering data could be accessed directly by retailers thus overcoming the need for monopoly distribution network businesses to be involved in providing data in the first place. ${ }^{10}$ This has become more feasible than in the past due to declines in smart metering technology costs and the rapid decline in the cost of embedded generation, particularly solar PV.

While problems that exist through the regulatory prescription of metering roles and responsibilities can be solved over the long run as new smart meter technologies are deployed, the long run could be quite long given current policy settings in jurisdictions other than Victoria, where a mandatory distributor led roll-out of smart metering technologies is underway. In the interim, it is necessary to analyse whether the metering principal-agent relationship between monopoly distribution network businesses and energy retailers is imposing sufficiently poor service levels and excess costs on the community, be that direct costs or wealth transfers amongst participants, to warrant further investigation and subsequent microeconomic reform. This multidimensional problem is analysed in Sections 4-6.

\section{The quality and timeliness of metering services in the National Energy Market}

To determine the quality of metering services within the energy market, we have extracted metering and energy consumption data from AGL Energy Ltd's ("AGL”) billing system for a 12 month period. ${ }^{11}$ This annual sample size for electricity and gas meter reads is 16.8 million and

\footnotetext{
${ }^{9}$ We should however note that there are many reasons for delays in issuing customer bills beyond meter data errors and it would be disingenuous of us to suggest otherwise. For example, in 2008/09 AGL's roll-out of a new \$200 million integrated customer billing platform was responsible for the delay of about $7.5 \%$ of the customer base for unacceptable periods, in some cases by up to 12 months.

${ }^{10}$ The widespread substitution of Type 6 'dumb' meters with Type 4 smart meters would also allow the industry to optimise energy pricing for peak, critical peak and off-peak periods thus ensuring that prices reflect the true cost of energy supply, and shift to (accurate) monthly energy bills which would reduce bill shock and make household budgeting easier.

${ }^{11}$ As indicated in AGL (2009), p.12, AGL has a single billing platform implemented by SAP which provides for enhanced customer service and data integrity.
} 
10.0 million respectively. AGL has approximately 3.4 million accounts and a market share of about $25 \%$, with substantial operations in each jurisdiction. As a result, we believe the data is likely to be sufficiently representative of the broader industry.

Applied research in the energy sector in relation to key drivers of customer satisfaction invariably concludes that 'getting the basics right' - i.e. timely and accurate billing - is quite fundamental (Accenture, 2012). As bills are typically seasonal in nature, the extension of time between two billing cycles due to late metering data can create bill shock events and in turn, payment difficulties for customers. In a rising cost environment (see Simshauser, Nelson and Doan, 2011) as is currently the case with electricity in Australia, the impact of late metering only serves to amplify the potential for bill shock. To assess the timeliness of metering, our sample billing data was analysed to determine how many meter reads were received late, and the duration of late meter reads. Under the Rules, meter data is required to be provided within two business days for electricity and one business day for gas after the end of a quarterly billing period. We explicitly assume that meter reads of up to four business days late impose only trivial costs on energy retailers and customers, and so we have opted to ignore these short delays. Our focus then, is on more serious delays which we define as five days or more. On this basis, our analysis revealed that for our sample of electricity customers, 807,159 meter reads $(4.8 \%)$ were late by five days or more. The distribution of the late meter data is presented in Figure 1.

Figure 1: $\quad$ Frequency Distribution of Late Electricity Meter Reads $(\mathbf{n}=\mathbf{8 0 7}, 159)$

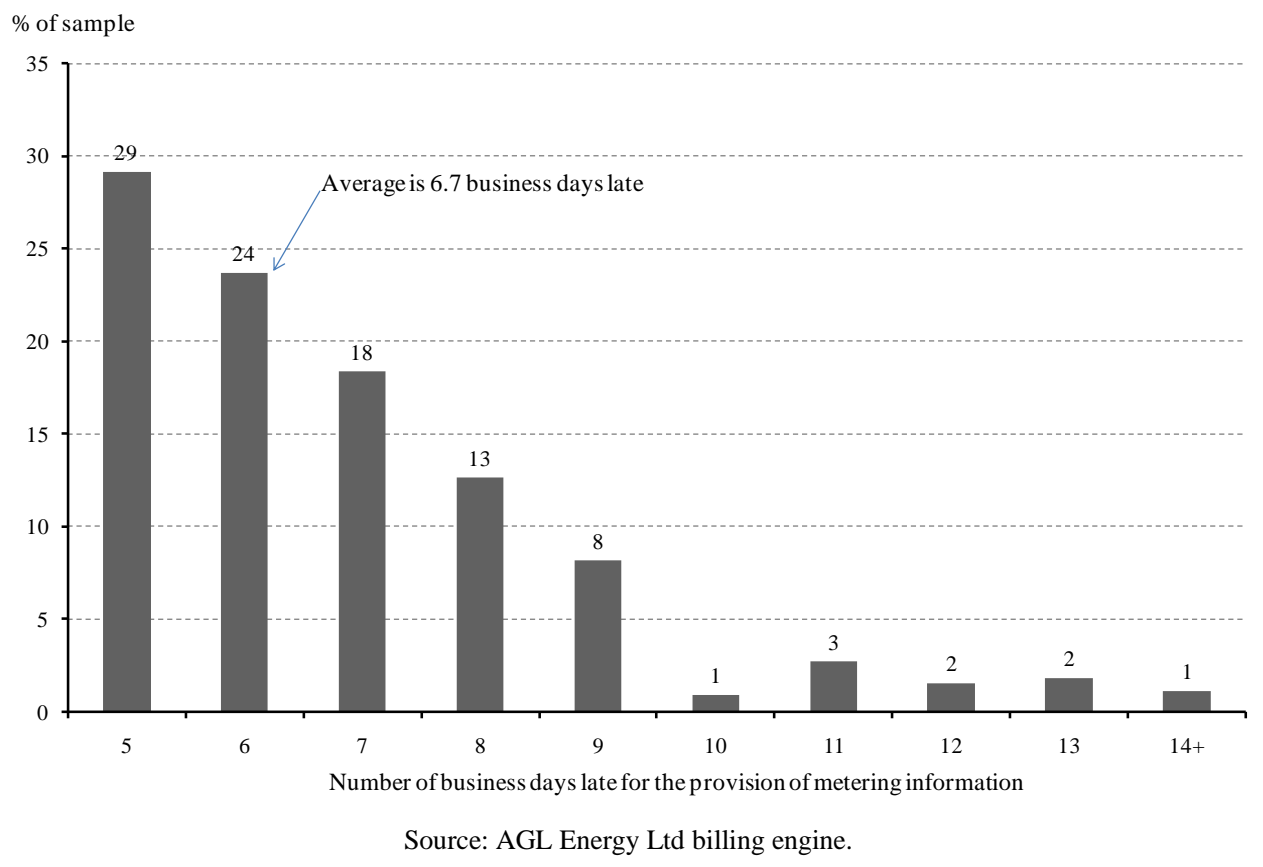

Figure 1 reveals that most late reads are received within two weeks of the required date (i.e. within 10 business days). We further segmented the late meter data by all monopoly distribution network providers in the market and found the average duration of late meter readings was broadly consistent across the market, with the overall market average of 6.7 'days late'. Note that the names of the firms have been withheld given that they are merely acting on the regulatory incentives that they face. 
Figure 2: $\quad$ Average Number of Days Late for Electricity Meter Reads by DNSP $(n=807,159)$

Average no. days
late



Source: AGL Energy Ltd billing engine

At first glance, Figure 2 tends to indicate that to the extent that late meter reads are a problem, a systemic issue exists since the duration of 'days late' result by networks spans a particularly tight range of 6-8 days around the market average of 6.7 days. This is not, however, a correct conclusion. The incidence of late reads is skewed towards a small number of monopoly distribution network providers. Energex in Southeast Queensland, for example, has a negligible number of late meter readings each year with less than $2 \%$ of their data provided outside the 4 'days late' window. Yet late reads by other network monopolies are, in some cases, more than 10 times those of Energex. Figure 3 illustrates the distribution of late read results by network patch. Such wide variations in late meter readings within a single market are particularly hard to explain. Taken as a whole, about 1-in-20 meter reads are received after the required date - noting that this excludes substitute meter reads.

Figure 3: $\quad$ Late Electricity Meter Reads by DNSP $(\mathbf{n}=\mathbf{8 0 7 , 1 5 9 )}$

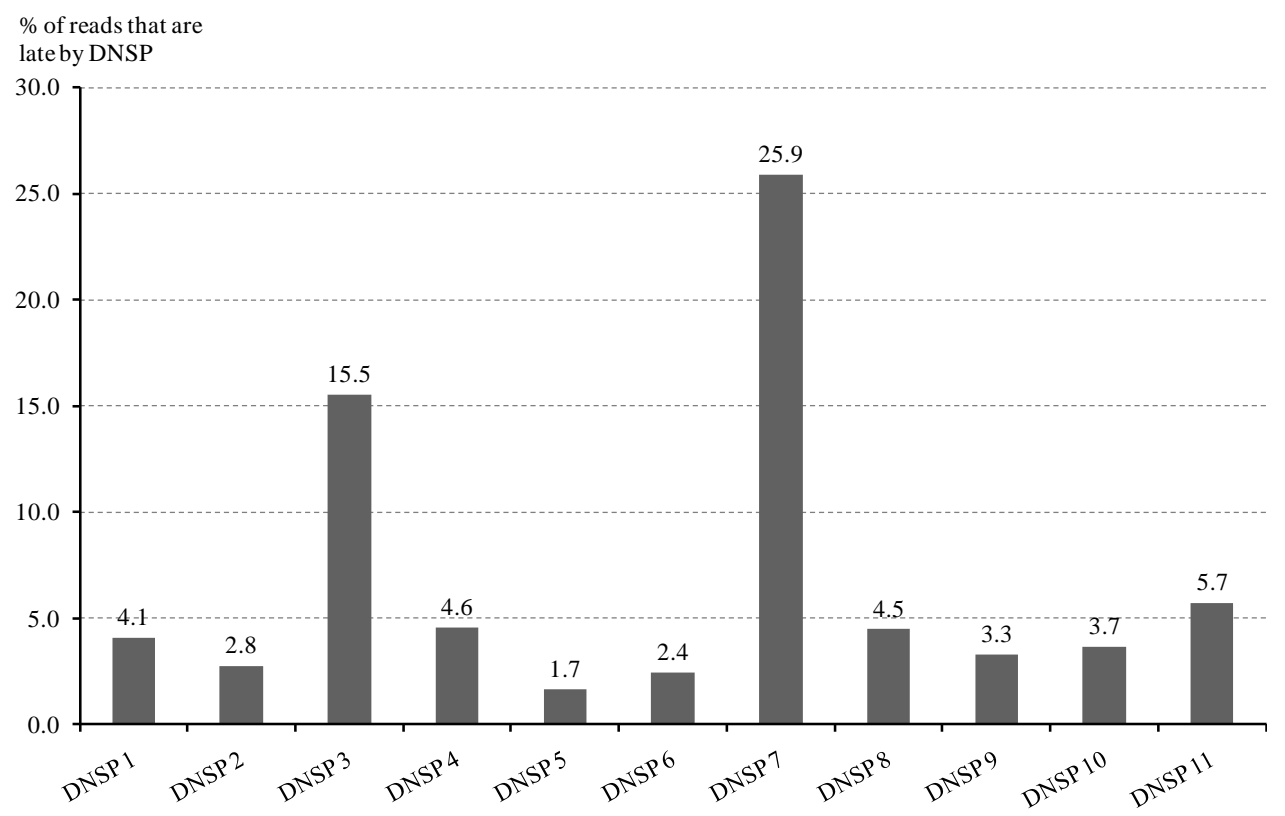


The data set for natural gas metering reveals a less uniformly distributed problem. About 1.9 million $(22 \%)$ gas meter reads were received more than two days after the required date. The duration of late reads is presented in Figure 4.

Figure 4: $\quad$ Frequency Distribution of Late Gas Meter Reads $(\mathbf{n}=\mathbf{1 , 9 4 0 , 0 0 3 )}$

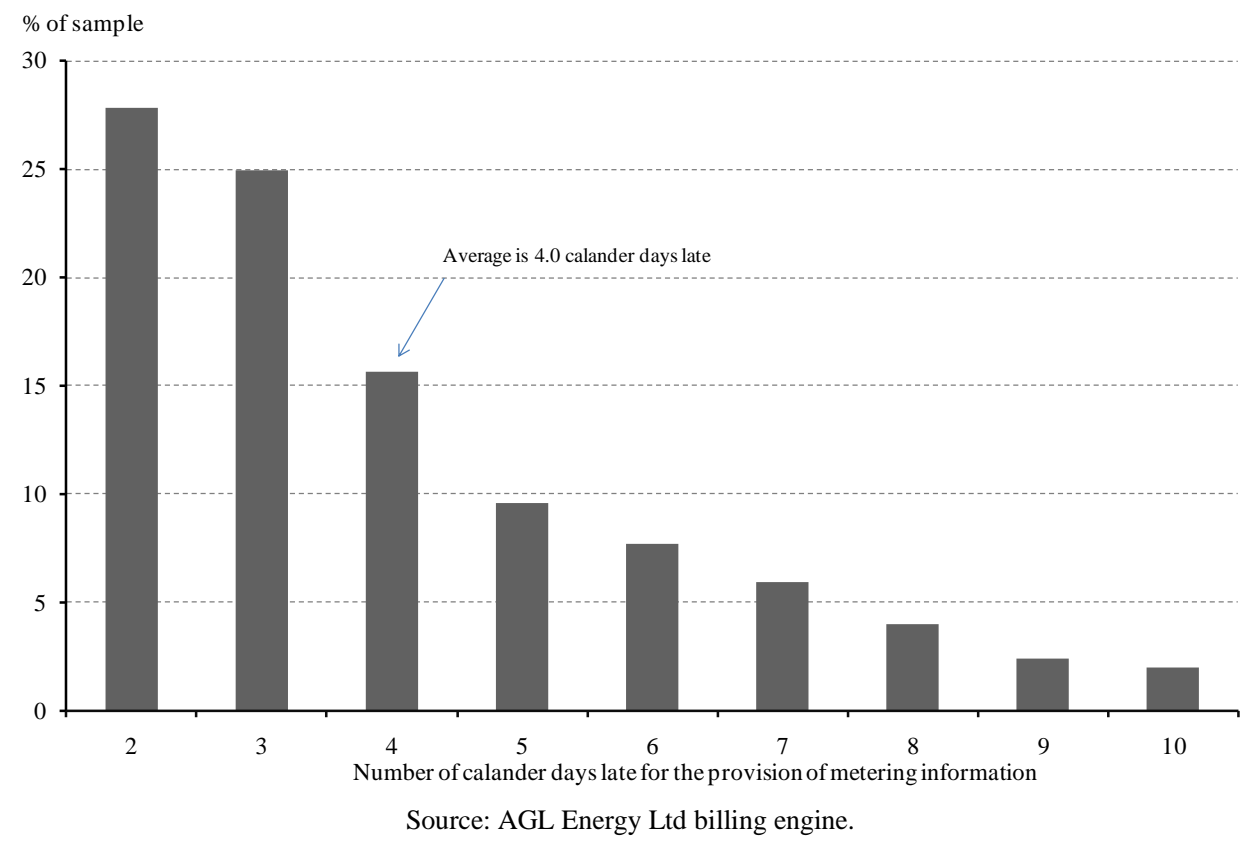

Figure 4 reveals that the vast majority of late gas meter reads are only marginally late, with an average duration of 4.0 days, considerably lower than that of electricity markets ( 6.7 days). Importantly, and unlike electricity metering, late gas metering data is concentrated within two network areas. Figure 5 shows the percentage of late gas meter reads by gas distribution network provider - note that in two particular network areas, about one in two meter reads are provided after the required date. However, unlike electricity markets, the other six network businesses provide late meter reads in less than $1 \%$ of cases which seems to indicate that high performance is possible. 
Figure 5: $\quad$ Late Gas Meter Reads by DNSP $(\mathbf{n}=\mathbf{1 , 9 4 0 , 0 0 3})^{12}$

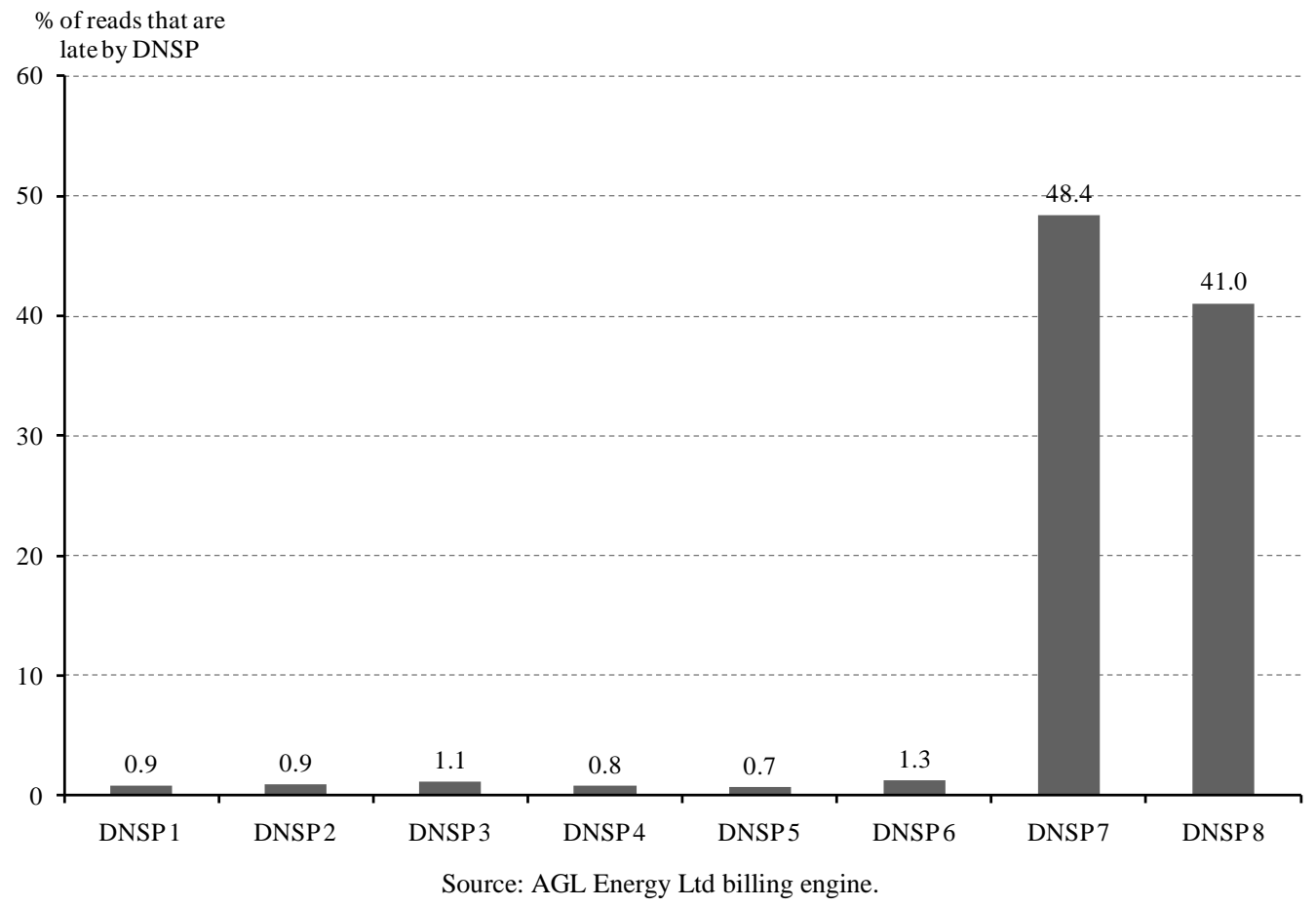

The costs associated with disruption to billing systems manifest themselves in late issuance of bills, poor customer experience and the cost of the subsequent response from customers (i.e. their own inconvenience and opportunity cost of the time taken to make complaint calls). Quantifying these costs is not easy. In fact, we do not believe that the methodology we outline below is conclusive but it is indicative of the cost incurred.

As a result of being unable to issue bills in a timely manner, energy retailers require greater working capital to accommodate delayed cash receipts from customers. We quantify the direct business costs and the extent of wealth transfers associated with delayed receipts from customers. This can be calculated by reference to the following formula:

$w=\left(p_{e} \cdot q_{e} \cdot m_{l}\right) \cdot\left(d_{l+2} \div 365\right) \cdot \beta_{i}$

Where $w$ is the wealth transfers arising from late reads;

$p_{e}$ is the unit price of energy, electricity $(\$ / \mathrm{MWh})$ or gas $(\$ / \mathrm{GJ})$;

$q_{e}$ is the quarterly quantity of energy consumed, electricity (MWh) or gas (GJ);

$m_{l}$ is the number of meter reads per annum defined as 'late';

$d_{l}$ is average 'days late' for cumulative meter reads plus 2 days for bill processing;

365 is the number of days per annum; and

$\beta_{i}$ is the weighted average cost of capital for the $\mathrm{i}^{\text {th }}$ energy retailer

We make use of published average energy price $p_{e}$ and energy consumption $q_{e}$ data (excluding carbon price impacts ${ }^{13}$ ), all of which is listed in Table 1 . Variables $m_{l}$ and $d_{l}$ have already been

\footnotetext{
12 The DNSP's for electricity and gas (i.e. DNSP 1, 2 etc) are different due to different entities operating in different geographical areas.

${ }^{13}$ Carbon pricing has been excluded to reflect the likely scenario that carbon prices will be removed from electricity prices following the repeal of the carbon pricing legislation at some point in 2014.
} 
defined above in Figures 2 and 4, and for $\beta_{i}$ we use $12 \%$ as the appropriate opportunity cost of funds employed.

Table 1: Quarterly average energy quantity and energy tariff data

\begin{tabular}{|c|c|c|c|c|}
\hline Region & $\overline{\text { Elec }}$ & Gas & Elec & Gas \\
\hline & (MWh) & $(\mathrm{GJ})$ & (\$/MWh) & $(\$ / G J)$ \\
\hline Qld & 1.9 & 8.1 & 204 & 46 \\
\hline NSW & 1.8 & 5.8 & 238 & 27 \\
\hline VIC & 1.4 & 16.5 & 240 & 16 \\
\hline SA & 1.5 & 7.0 & 277 & 33 \\
\hline Average & 1.8 & 5.8 & 239 & 27 \\
\hline
\end{tabular}

Solving equation 1 for both gas and electricity results in transfers of wealth from principal to agent of $\$ 1.03$ million, with the cost essentially borne directly by (in this case) the retailer, AGL. We have no reason to expect that the same methodology would not yield equivalent results for all other energy retailers in the market. Accordingly, if we assume that these efficiency losses are distributed across all energy retailers in a uniform manner, and that each have a similar cost of capital, the total losses arising from metering delays is \$4.1 million per year (based upon AGL's current market share of approximately $25 \%$ ).

\section{Estimated and erroneous meter reads}

With Type 5 and 6 meters, physical attendance is required in order to read the meter data. As such, there are instances of estimated and erroneous meter reads. The results of our analysis of AGL's billing engine are presented in Table 2.

Table 2: Estimated accounts

\begin{tabular}{ccccc}
\hline & Invoices & Estimated & Percent & Ratio \\
\hline Electricity & $7,918,479$ & 618,247 & $7.8 \%$ & 1 in 13 \\
Gas & $6,906,153$ & 563,769 & $8.2 \%$ & 1 in 12 \\
\hline Total & $14,824,632$ & $1,182,016$ & $8.0 \%$ & 1 in 13 \\
\hline \multicolumn{5}{c}{ Source: AGL Energy Ltd billing engine. }
\end{tabular}

As Table 2 highlights, in 12 months AGL issued 14.8 million invoices, and almost 1.2 million of these were estimated invoices due to the meter data being estimated. Put another way, $8 \%$ of all invoices, or 1 in 13 invoices issued, necessitated an 'estimation' of actual consumption. The issue here for policymakers is quite straightforward when considered in the context of other industries. For instance, it is unlikely that the consumers would accept supermarket performance if 1 in 13 items passing through the scanner at the cash register was quantity estimated, and settled accurately during a subsequent visit to the store.

In practice, there are a number of reasons why electricity and gas meters are estimated rather than physically read. These include doors and gates being locked thus preventing access to the meter, perceived dangers such as dangerous animals and access not being available through keys not working on meter box locks, and so on. The Essential Services Commission (2008) determined that for all regions surveyed in Victoria, between $50 \%$ and $85 \%$ of estimated reads were attributed to lack of access to meters. This raises the simple question of why, given the reduction in technology costs over the past decade, smart meters are not simply mandated in such instances where genuine and systemic failure occurs with meter reading.

We noted earlier that the applied consumer market research invariably reveals that one of the most fundamental drivers of customer satisfaction in relation to energy is to simply ' $\mathrm{get}$ the basics 
right'. It is clear that estimated meter readings and the associated invoice are highly problematic from a customer experience perspective. However, more substantive problems arise when meter reads are deemed "wrong" as a consequence of a customer 'high bill' inquiry. These incidents result in a meter investigation where a meter is faulty or an incorrect meter reading has been obtained, or where a meter reader is aware that a current reading is effectively correcting a prior error. The number of wrong meter reads within the AGL Energy billing sample is material, amounting to 1,491,698 and 289,771 for electricity and gas respectively during our observation period. This represents $8.9 \%$ and $2.9 \%$ of all meter readings in our sample. It is unclear why so many meter reads are deemed wrong, but the consequences are significant. Where a meter read has been declared wrong, the subsequent billing period typically incorporates the additional charges associated with the corrected information. This invariably results in bill shock and rising customer complaints.

There are a number of impacts associated with the continued use of estimated and wrong meter data that are experienced by both industry participants and consumers. We have categorised these impacts into two broad areas: deadweight losses associated with customer complaints due to access disputes, wrong meter reads, and adverse customer experience. We have used the term deadweight loss to describe costs associated with customer complaints where they represent a loss of consumer surplus or producer surplus. These are discussed in greater detail below. Given the number of incidents within any given year owing to metering issues, it is inherently difficult to determine deadweight losses associated with customer complaints and so we necessarily make assumptions to quantify their impact on the industry, that is, the direct business costs and the extent of deadweight losses by reference to the following formula:

$d=\left(c_{v} \cdot c_{c} \cdot 1 \cdot 5 \cdot r_{r c}\right)+\left(m_{s} \cdot m_{c}\right)+\left(o_{v} \cdot c_{c}\right)$

Where $d$ is the deadweight loss;

$c_{v}$ is the total 'call volumes' processed by AGL at its customer call centres, and amounts to 85,000 calls per week or about 4.4 million annually;

$c_{c}$ is the time-in-motion 'call cost' of processing the average in-bound customer phone inquiry and equals $\$ 9.86$;

1.5 is an input variable which estimates the extended nature of more serious complaint calls as distinct from an average in-bound customer call; and

$r_{r c}$ is an estimate of the ratio of phone calls in which the root-cause of the call can be traced back to meter data errors, erroneous meter reads and invoices (based upon the AGL experience, this variable is $30 \%$ although it could be higher or lower for other retailers);

$m_{s}$ is the number of special meter reads to correct errors and is currently 22,792 per annum;

$m_{c}$ is the average cost of special meter reads and is $\$ 30$ per read;

$o_{v}$ is the total volume of ombudsman complaints arising from metering errors imposed on energy retailers and is 2,000 per annum (AGL's share); and

$o_{c}$ is the average cost dealing with an ombudsman complaint on metering and is $\$ 650$.

Solving for equation 2 equals $\$ 28.0$ million per annum in deadweight losses, based on the AGL data set. Given that AGL represents about one-quarter of the market, this amounts to a $\$ 112.1$ million problem for the industry per annum. This is a large cost impost, particularly if considered in a valuation exercise in which such costs are assumed to go on into perpetuity. But we should note two key issues at this point. First, some proportion of those complaints will be just as much the fault of the energy retailer as monopoly distribution network businesses. And second, any change in policy will not necessarily eliminate all errors from occurring into the future. However, unless some form of financial incentive or policy directive (e.g. smart meter roll-out) exists to remedy such issues, they will not improve either. 
Ongoing estimated and wrong reads result in poor customer service and we have not attempted to quantify the costs to consumers related to invested time and emotional distress. These attributes of the problem have been noted in the mainstream media in the context of disputed bills, perceptions of high bills, and ongoing uncertainty and household budget impacts about the possibility of "catch-up" bills (see for example Rolfe and Lentini, 2011). The Essential Services Commission (2008, p.18) articulates the issues related to customer experience best when it stated that, 'the Commission notes that despite adherence to procedures, accounts based on estimated reads may result in unexpectedly high bills that do not reflect actual consumption'.

The long-term solution to reducing the costs associated with estimated and wrong meter reads is the introduction of remotely read smart metering technologies. However, it will be many years before such a policy is widespread through eastern and southern Australia given the experience in Victoria thus far. ${ }^{14}$ In the short-term, the ongoing lack of accountabilities for energy retailers and monopoly network distribution businesses is likely to see these costs continue to manifest and result in a very poor customer experience for those affected.

It is important to note how existing resolutions to the issue of estimated reads are articulated within the existing metering regulatory framework. Clause 2.1 of the Metering Code reinforces the obligations that are stated in the Retail Code and the Distribution Code about customers providing access to metering installation (see National Energy Customer Framework, 2011; National Gas Rules, 2011; and National Electricity Rules, 2011). Provided official identification is shown, a customer must at all times provide "convenient and unhindered access" to the monopoly distribution network business or its authorised representative. Additionally, customers are obliged under the Metering Code to inform the monopoly network or energy retailer as soon as practicable if there is any change affecting access to the metering equipment.

Energy retailers are required to use their best endeavours to ensure that a customer's meter is read at least once in any twelve month period. There is, however, no express obligation for a monopoly network distribution business to obtain an actual read within the same timeframe. This is an unusual requirement given that monopoly network distribution businesses are the entities that actually read meters, and any contact with the customer by the energy retailer on metering issues requires that the monopoly network distribution business be informed. As the Essential Services Commission (2008, p.18) observed:

...estimated reads relates to meter access issues and distributors noted that they are reliant on retailers to ensure that access to meters is provided. If meter access is assured, distributors generally noted that there would be little need for estimated reads."

In submissions to the Essential Services Commission's 2008 inquiry into estimated reads in Victoria, most monopoly distribution network businesses noted that where a customer is responsible for hindering access to meters on three successive occasions, energy retailers have the legal right to disconnect the customer, and queried why energy retailers do not utilise this option. We have not asked this question of the relevant decision makers at AGL, nor any other retailer for that matter because the answer seems rather intuitive. Energy retailers incur 100\% of the bad debt that would be subsequently written-off, whereas monopoly network distributors will have received their network revenues from the relevant retailer in a timely manner - regulations instruct them to do so. Furthermore, if the energy retailer opted to disconnect the customer, as we later reveal, the chance of success would be just $33 \%$ on average, so a disconnection order would more than likely be ineffective in any event.

${ }^{14}$ In Victoria, a mandated smart meter roll-out was met with a particularly vocal consumer backlash. The policy objective function was entirely sensible, but policy implementation was poorly designed and executed. 
While it may be reasonable for energy retailers to assume that monopoly network distribution businesses are responsible for overcoming issues related to estimated reads due to their on-theground knowledge of which customers' meters are being estimated, it is equally reasonable for monopoly network distribution businesses to assume that energy retailers will resolve issues related to estimated meters due to the requirements of the regulatory framework. This is, therefore, a vexed issue to resolve without policy reform.

\section{Service provision: energisation and de-energisation services}

While the focus of this article is on the quality of customer service as it relates to metering, the embedded regulatory-defined relationship and the principal-agent problem is also having an adverse impact on other aspects of energy supply, most notably, connection and disconnection from the grid. This involves defined roles for energy retailers and monopoly network distributors in relation to the connection and disconnection of premises, and has been the subject of some debate around the lack of regulatory requirements to overcome efficiency losses arising from the requisite principal-agent relationship. Under current regulatory requirements, energy retailers are responsible for informing monopoly distribution network businesses when a premise is required to be connected or disconnected. In relation to disconnection, there are generally two reasons driving service order requests:

- Move-outs: when a customer moves house, there is no consumer responsible for electricity consumption that the premise may continue to consume and so disconnection from the grid is required. Failure to disconnect a premise results in the risk of ongoing consumption arising from generation and network costs, with virtually no prospect of debt recovery.

- Payment failures: where customers who have failed to pay their bill and have not responded to the various levels of credit notices, and as such have simply disengaged with their energy retailer, disconnection becomes the only remaining avenue open to energy retailers since ongoing connection merely results in heightened bad debts which can only then be recovered by raising future energy tariffs to all other customers.

Once an energy retailer has identified a need for disconnection for either reason (i.e. move-out or disengaged customer), a service order is raised with the host monopoly distribution network business, who in turn has a responsibility to carry out the disconnection notification, be that by way of removing a fuse on the premise or physical disconnection from the network at the point of supply on the nearest electricity pole or gas supply point.

Utilising the same methodology to that employed in Sections 4 and 5, we have made use of the data from AGL Energy Ltd's billing platform to analyse the performance of connection and disconnection services. Our data sample contains 69,448 electricity connection and disconnection service orders and 138,713 gas orders. Figure 6 shows completed orders on the left, and non-completions on the right. 
Figure 6: Frequency Distribution of Service Orders Completed/Not Completed Service Orders

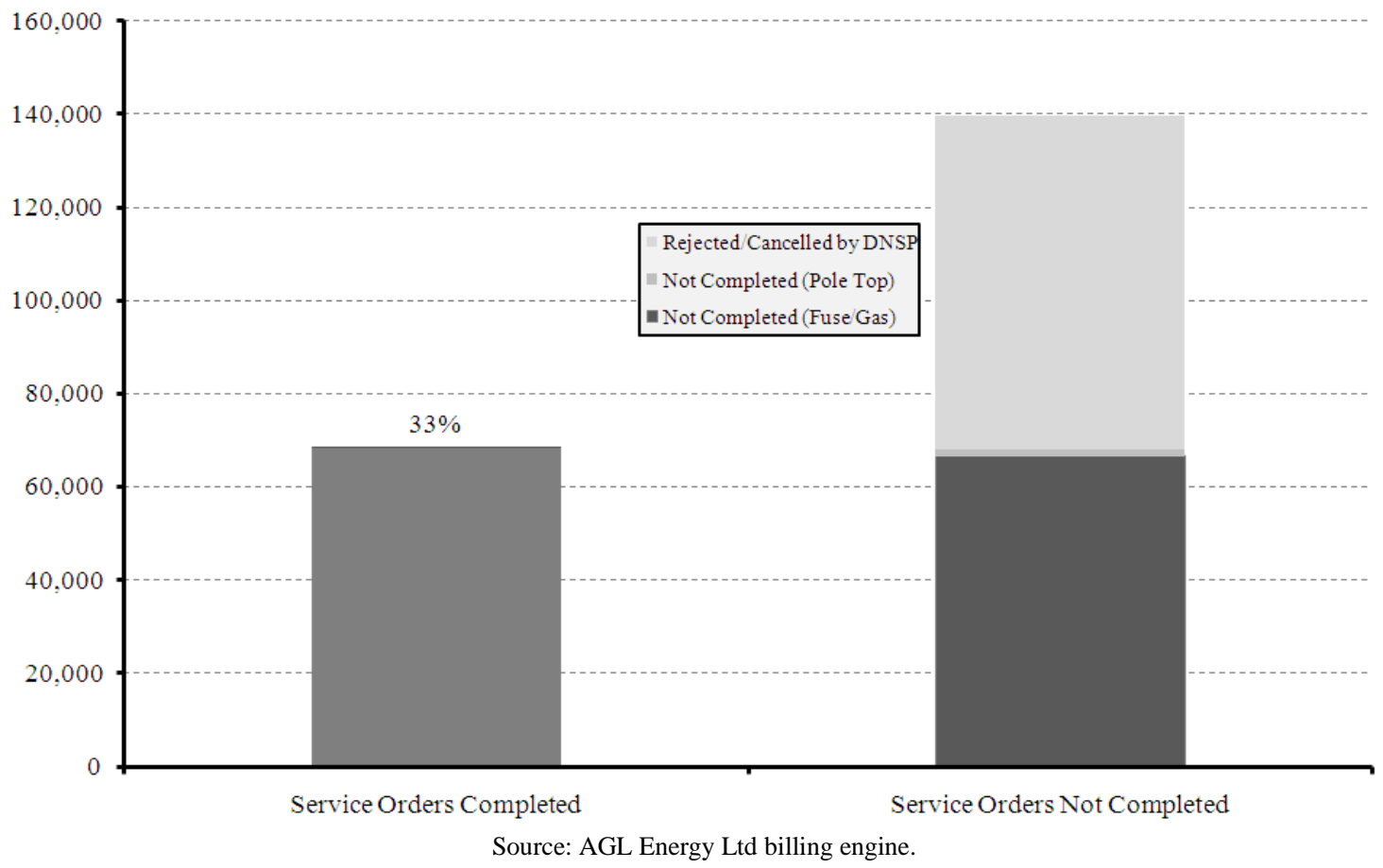

Of the 208,161 service orders raised, almost 140,000 (67\%) of connection or disconnection orders were 'Not Completed'. Figure 6 also shows the breakdown by service order type. One might expect that failure rates are the result of the more complex 'pole top disconnection and reconnection' failures. But as Figure 6 reveals, these complex disconnections represent only a small fraction of failed orders, at just $1.1 \%$. The completion rates vary considerably amongst monopoly network businesses, as Figure 7 reveals. 
Figure 7: Distribution of completion rates by monopoly network



Figure 7 raises the question of why one network company can deliver superior performance relative to other networks. The absence of visible incentives to improve performance is the most plausible explanation. Far from having incentives to improve outcomes, the existing framework enshrines suboptimal performance because failed service orders are not refundable. That is, charges by monopoly distribution network businesses for failed service must nonetheless be paid. And crucially, when a failed service order is requested for a second time, it is charged again, and at the same rate. This charging continues on a cumulative basis at prevailing rates until the service is completed or a further service order is not requested.

Each monopoly network has a different charging structure, ranging from about $\$ 20$ to $\$ 96$ per event, with an average of $\$ 36.71$ per connection/disconnection. So for example, if a monopoly distribution network company charges $\$ 42.80$ to disconnect a premise and takes three attempts to complete the order, the energy retailer will incur $\$ 128.40$ (i.e. $3 \times \$ 42.80$ ). As Figure 7 illustrates, only $33 \%$ of service orders are on average completed, which in AGL's instance resulted in direct losses of $\$ 1.5$ million per annum arising from failed service orders during the 12 month period. Since AGL represents about $25 \%$ of the market, total cost inefficiencies to the industry amount to about $\$ 6.0$ million per annum. Figure 8 outlines the total costs associated with service orders not completed for AGL Energy Ltd broken down by network region. 
Figure 8: Annual cost of incomplete service orders

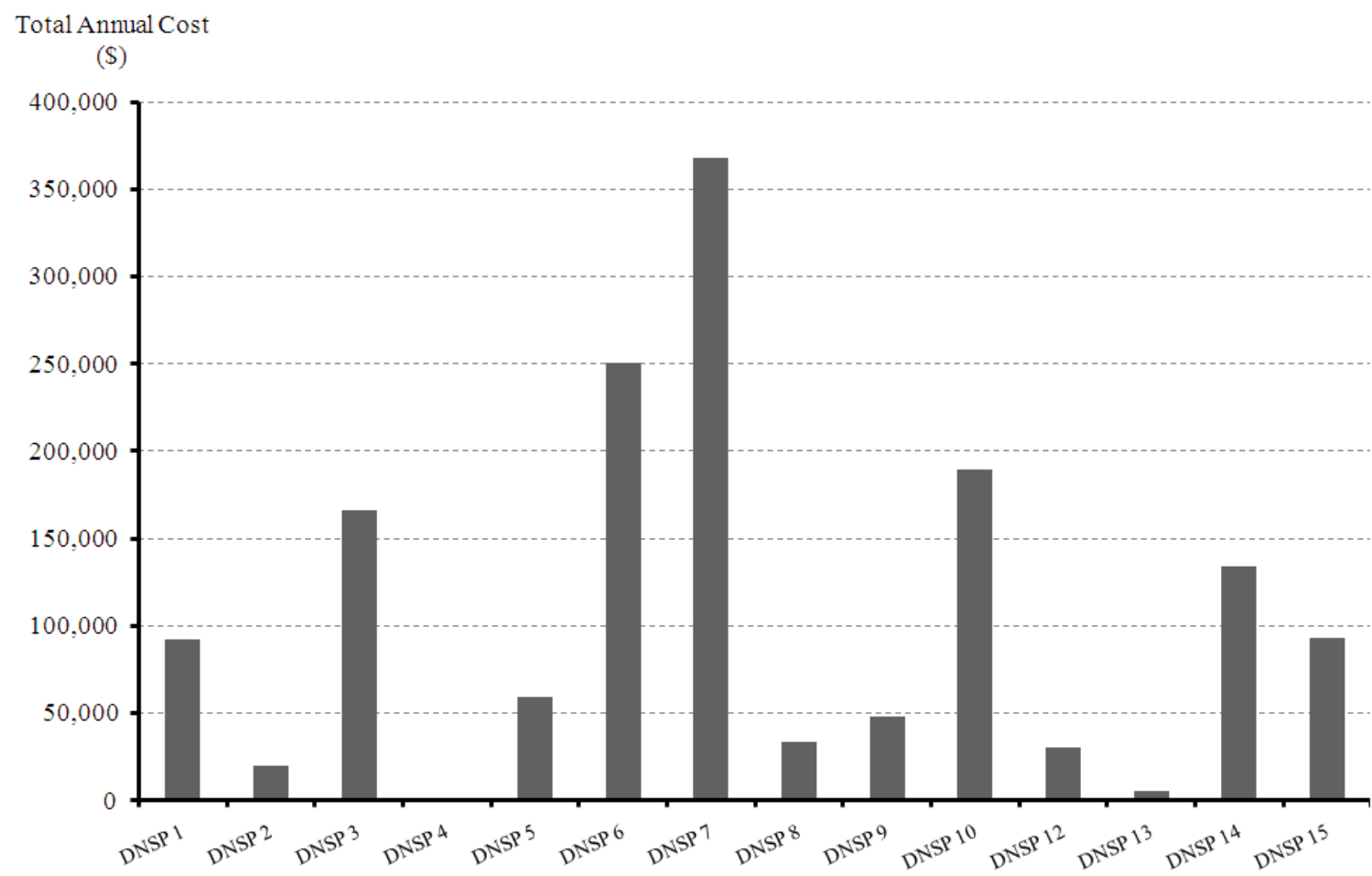

Source: AGL Energy Ltd billing engine.

While the direct cost of failed service orders is material, there are added losses associated with service failure. This is highlighted in Figure 9, where AGL's aggregate annual electricity 'disconnection' orders are represented by the first bar, and total 54,327 requests. The subsequent bars illustrate the distribution of 'attempts' to achieve disconnection.

Figure 9: Disconnection attempts (success rate)

Disconnection Orders

(electricity only)

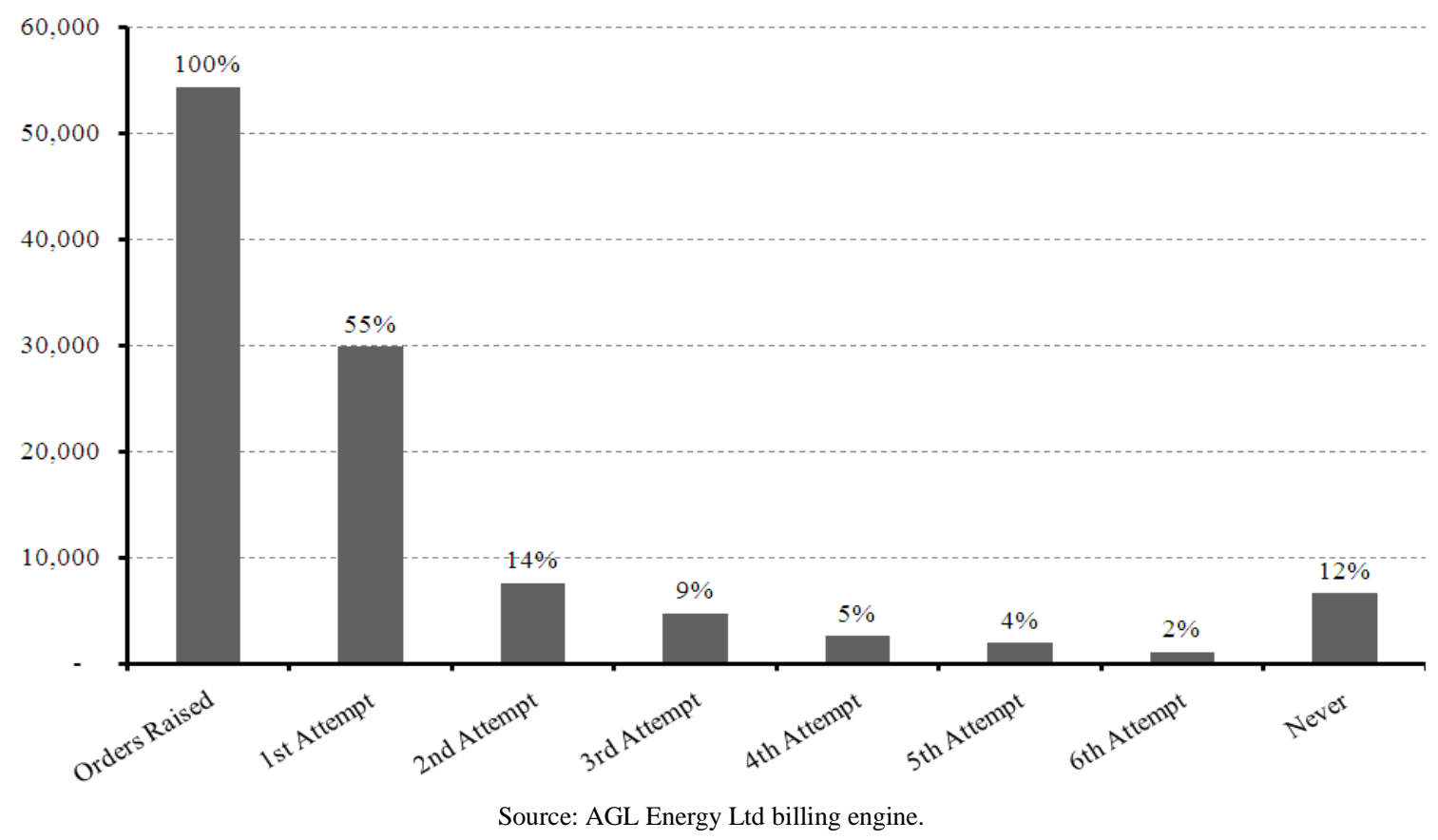


Note that about 30,000 (55\%) electricity disconnection requests are successfully achieved on the first attempt. We noted earlier that the total cost of repeat orders was $\$ 1.5$ million and is effectively a deadweight loss. What this result did not capture was the additional losses associated with the more than $6,600(12 \%)$ requests that were never completed. The cycle time taken to raise and execute a service order is typically 7-10 days. On this basis, it is not unreasonable to presume that 6 attempts would result in 80-90 days of ongoing consumption from the grid, and under such conditions, is would seem unlikely to be recovered. Given average price and consumption data from Table 1, and the 6,600 requests never completed in Figure 9, this results in a further $\$ 2.8$ million in losses, assuming disconnection eventually occurs after 90 days. Assuming all other accounts are recovered (which is unlikely), the opportunity cost of working capital adds a further $\$ 0.2$ million, thus totalling about $\$ 3.0$ million. This amounts to unrecovered consumption and losses of $\$ 12$ million across the broader market.

As in the case of estimated and late reads of electricity and gas metering, it is primarily the principal-agent relationship that results in these deadweight losses and transfer costs. The incentive to see the disconnection or reconnection service orders completed resides with energy retailers, as customer experience and liability of premise consumption is the responsibility of energy retailers. However, the ability to implement service orders resides with the monopoly network distribution business. As the incentives are not aligned, there is a classic principal-agent problem.

\section{Policy Implications and Concluding Remarks}

In this article, we have analysed the extent to which a principal-agent problem exists in relation to electricity and gas metering. Our analysis has revealed that the direct and opportunity losses are material. Service levels are relatively poor across several areas of metering services provision. We have found that $5 \%$ of electricity meter reads are late with $1 \%$ received more than 3 weeks after the due date for billing purposes; $22 \%$ of gas meter reads are late; around 1 in 13 meter reads is estimated and a further 1 in 11 is wrong; and 2 in 3 disconnection/connection service requests are not completed, but are nonetheless paid for. The inadequacy of the regulatory framework creates a principal-agent problem in the first instance. The monopoly distribution network businesses are responding to the incentives that they face.

Based upon our study of data obtained from the AGL Energy billing system, we have established that transfer costs and deadweight losses are a consequence. Using a relatively simple methodology $\$ 16.1$ million in costs have been identified that are transferred from the agent (monopoly distribution network businesses) to the principal (energy retailer) and \$118.1 million in deadweight losses have been identified within the industry in the 12 month sample period. A summary is presented in Table 4.

Table 3: Estimated Total Annual Costs Associated with the Principal-agent Problem

\begin{tabular}{c|cc}
\hline Cost Description & Deadweight Loss & Wealth Transfers \\
\hline $\begin{array}{c}\text { Late provision of } \\
\text { metering data } \\
\text { Costs related to } \\
\text { estimated reads }\end{array}$ & $\$ 112.1$ million & \\
$\begin{array}{c}\text { Service quality costs of } \\
\text { connection services }\end{array}$ & $\$ 6.0$ million & $\$ 12.0$ million \\
Total Costs & $\$ 118.1$ million & $\$ 16.1$ million \\
\hline
\end{tabular}

Another important finding from our research is that 1 in 13 electricity or gas meter reads is estimated. It is inconceivable that consumers would accept this level of service in other markets 
such as retail supermarkets. Rolfe and Lentini (2011) tracked the complaint of a customer in relation to a gas bill where consumption had reportedly grown by 2750 percent in a single year (due to an estimated read). Ironically, the network business expressed surprise at the reaction of the customer and the presiding retailer, claiming that retailers sought more estimated reads, not less.

To the extent that a proportion of these deadweight losses are not absorbed by retailers and are passed on to consumers, they have a disproportionately greater impact on low-income consumers of energy. Nelson, Simshauser and Kelley (2011) and Nelson, Simshauser and Nelson (2012) demonstrated that costs passed through to end consumers tend to have a regressive impact due to the consumption profiles of various households broken down by income grouping. As such, the evidence presented in this article needs to be considered in both social equity and economic efficiency contexts.

The critical question for policymakers, in light of our analysis, is how to overcome the issues which manifest as a result of the underlying principal-agent problem. However, prior to considering actual recommendations for reform, policymakers need to consider policy principles to guide decision making. This is complicated by the dynamic nature of metering technology as it is continuously evolving, falling in cost, and becoming more widely available. We believe that the following policy principles are worth pursuing:

- All aspects of metering should be contestable unless there is no alternative. Adoption of this principle would effectively make the principal-agent problem, as it currently exists, redundant. Customers are the ultimate owners of their metering data and should have greater choice in accessing metering technologies that suit their circumstances. This framework is currently practiced in the Commercial and Industrial market, where customers choose a Meter Provider of choice via their energy retailer. This choice should be enhanced, not extinguished, by regulatory instruments.

- Metering charges should be separated from network supply charges. Unbundling meter charges from network supply charges is the main barrier for type 4 remotely read metering being adopted more broadly by small business and residential customers outside of mandated roll-out policies. Unbundling metering charges effectively facilitates greater customer choice and will create opportunities for a competitive roll-out of remotely read meters.

- The customer should not bear the risk of stranded assets. If a distribution network monopoly business or energy retailer invests in a metering technology which subsequently becomes redundant, the provider, not the customer, should be responsible for the ongoing financial liability associated with the redundant technology. Consumer protection is also required for customers to ensure that metering products are not inoperable with energy sector standards, and that an existing interval meter could not be replaced by a suboptimal technology.

- Competitive neutrality should remain a core principle underpinning all energy market reforms. Where regulated businesses are involved in the provision of competitive metering services, ring fencing arrangements and appropriate customer protection frameworks need to be in place to ensure that regulated revenue is not used for unregulated services.

In applying these policy principles in assessing options for reform, we see two potential solutions. Importantly, these solutions are not mutually exclusive and could be adopted simultaneously. In the first instance, universal service level standards should be established by the Australian Energy 
Market Commission for some of the basic requirements related to metering on both energy retailers and monopoly distribution network businesses with penalties created to enforce compliance. This has been raised as a concept before by the Essential Services Commission in Victoria stating that it has been asked in the past to consider such a proposal (see Essential Services Commission, 2008, p. 10). This option would ensure that where customers do not exercise 'metering choice', appropriate standards are in place for customers that remain on type 6 metering arrangements.

If monopoly network distribution businesses were required to provide data and services within strict timeframes across both gas and electricity markets in a consistent way, with appropriate enforcement mechanisms (e.g. penalties), it is likely that the costs identified in this paper would gradually reduce as service quality improves. Accordingly, we believe there is a strong case for Australian energy policymakers to review the issues identified in this article to examine whether there is a need for robust standards to be introduced, enforceable on both principal (energy retailers) and agent (monopoly network distribution businesses).

The second option for reform would be amending the National Electricity Law, National Gas Law and subordinate legal instruments to make metering services fully contestable. This is not without precedent. Such a framework currently applies in Australia for meter types 1-4 remotely read metering. New Zealand has also fully embraced the contestable metering framework model and allowed retailers to choose their metering provider. Extracts from the New Zealand regulatory framework are provided in Appendix 1. Importantly, this is an issue that the Australian Energy Market Commission is considering at the time of writing as a recommendation of the Power of Choice Review ${ }^{15}$.

Longer-term, the principal-agent issue identified in this paper is likely to dissipate with the proliferation of smart remotely read metering technologies, whether it is within a contestable or a monopoly framework. However, we believe that the market is many years away from seeing the widespread use of these meters based on current installation rates and current incentive structures. Accordingly, policymakers should consider whether there is in fact an economic or public policy case for the introduction of customer choice in the provision of metering services. The provision of consumer choice of metering type and provider would be likely to accelerate the adoption of the technology as consumers would benefit from innovative 'market-led' solutions such as inhome displays and Time-of-Use (ToU) pricing. If the current Rule change proposal being considered by the AEMC is not adopted and metering remains a monopoly service, we would recommend that policy makers establish minimum service standards which would prevent poor metering service outcomes, the source of which in our view is a classic principal-agent problem.

\footnotetext{
${ }^{15}$ Further information on the current Rule change is available at: http://www.aemc.gov.au/market-reviews/open/power-of-choiceupdate-page.html
} 


\section{References}

Accenture, (2012), "The new energy consumer - balancing strategic and operational objectives, Accenture Innovation Centre for Energy and Utilities", Available at http://nstore.accenture.com/acn_com/PDF/Accenture-Balancing-Strategic-Operational-Imperatives.pdf, Accessed on 13 August 2012.

AGL Energy Ltd (2009), AGL Summary Sustainability Report, AGL Publication, Sydney.

AAR: Allens Arthur Robinson (2011), "National Energy Customer Framework Update", Focus AAR Publication, Allens Arthur Robinson

Australian Financial Review (2011), "Now the banks say they just want to be loved", Australian Financial Review, 13 September 2011, Sydney, p. 48.

Berle, A. and Means, G. (1932), The Modern Corporation and Private Property, MacMillan, New York.

Energex, (2007), Annual Report, Energex Publication, Brisbane. Available at www.energex.com.au Accessed 28 February 2012.

Energy Supply Association of Australia (2008, 2010), Electricity Gas Australia, ESAA Publication, Melbourne.

Essential Services Commission (2008), Special Report - Use of estimated accounts by Energy Retailers, December.

Huysmans, J (2005), “Less than 160 MWh Meter Arrangements", Presentation to the Centre for Energy and Environmental Markets (UNSW), Available at http://www.ceem.unsw.edu.au/windworkshop/AMIworkshop2-1JeffHuysmans.pdf

Murtishaw, S. and Sathaye, J, (2006), Quantifying the effect of the principal-agent problem on US residential energy use, Energy Analysis Department, University of California.

NCC: National Competition Council, (2003), “2003 NCP assessment”, National Competition Council Publication, Melbourne. Available at http://ncp.ncc.gov.au/docs/2003\%20assessment.pdf

Nelson, T., Simshauser, P. and Kelly, S. (2011), "Australian residential solar Feed-in Tariffs: industry stimulus or regressive form of taxation?", Economic Analysis and Policy, Vol. 41 No. 2, pp.113-129.

Nelson, T., Simshauser, P. and Nelson, J. (2012), " Queensland Solar Feed-In Tariffs and the Merit-Order Effect: Economic Benefit, or Regressive Taxation and Wealth Transfers?", Economic Analysis and Policy, Vol. 42 No. 3, pp. 277-301.

Oakley Greenwood, 2010, "Benefits and costs of the Victorian AMI program", Final Report to the Department of Primary Industries, Oakley Greenwood Publication, Melbourne. 
Parer, W. (2002), "Towards a truly national and efficient energy market”, Council of Australian Governments Energy Market Review, Commonwealth of Australia, Canberra. Available at http://www.ret.gov.au/Documents/mce/ documents/FinalReport20December200220050602124631.pdf

Rolfe, J. and Lentini, R, (2011), “Huge gas bill is hot air”, The Daily Telegraph, p. 23.

Simshauser, P. (2012), "When does retail price regulation become distortionary", AGL Applied Economic and Policy Research, Working Paper No.33, Sydney. Available at www.aglblog.com.au

Simshauser, P., Nelson, T. and Doan, T. (2011), “The Boomerang Paradox Part 1: how a nation's wealth is creating fuel poverty", The Electricity Journal, Vol. 24, Issue 1, pp. 72-91. 


\section{Appendix 1: Extract from the New Zealand Regulatory Framework}

"The Code currently places obligations on a retailer responsible for an ICP to ensure meters provide metering data to the level of accuracy required for consumer billing and reconciliation purposes. The Authority does not view this obligation as establishing a right for those retailers to preclude other parties from providing metering services and metering data to consumers, and has decided not to establish a 'right' for any party to nominate the MEP nor to establish a 'right' for third parties to obtain access to metering data.

"The Authority considers that the metering services market in New Zealand is workably competitive, with multiple retailers, distributors and other parties obtaining metering services from competing meter owners/operators (ie MEPs). A regulatory intervention at this stage would likely hamper the efficient development and operation of the metering services market by diminishing the commercial and competitive incentives for the efficient provision and procurement of metering data and services. The Authority considers that commercial negotiations currently represent the most efficient approach for participants in the metering services market to obtain access to metering data and services for the long-term benefit of consumers." $i$

${ }^{\mathrm{i}}$ www.ea.govt.nz/document/16353/download/our-work/programmes/priority-projects/part-10-review/ 